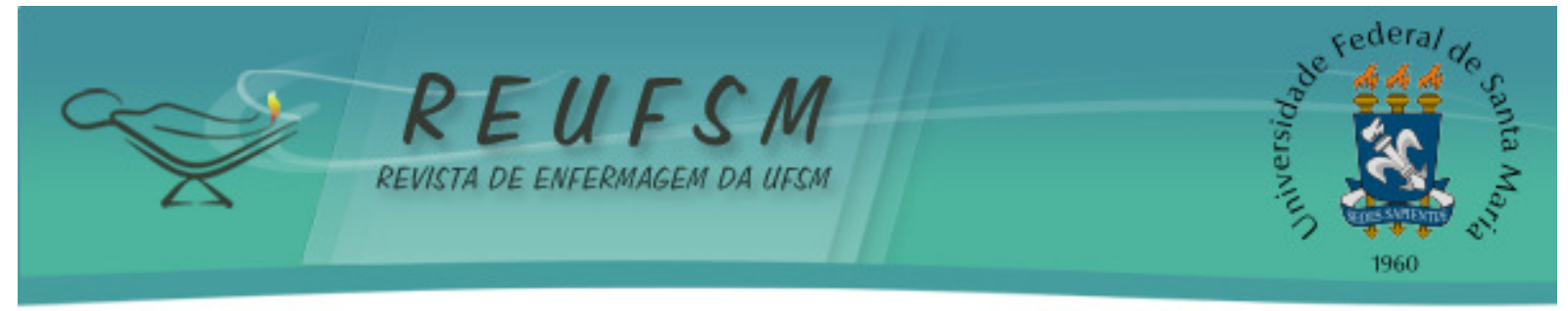

ARTIGO ORIGINAL

\title{
DIFICULDADES DO ENFERMEIRO NO GERENCIAMENTO DA UNIDADE DE PRONTO-SOCORRO HOSPITALAR
}

\section{DIFFICULTIES OF NURSES IN THE MANAGEMENT OF THE HOSPITAL'S EMERGENCY ROOM DIFICULTADES DEL ENFERMERO EN LA GESTIÓN DE LA UNIDAD DE URGENCIA HOSPITAR}

\author{
Thaís Vanessa Bugs ${ }^{1}$ \\ Denise de Fátima Hoffmann Rigo ${ }^{2}$ \\ Cristina Daiana Bohrer ${ }^{3}$ \\ Fabieli Borges ${ }^{4}$ \\ João Lucas Campos de Oliveira ${ }^{5}$ \\ Nelsi Salete Tonini ${ }^{6}$
}

Doi: $10.5902 / 2179769223374$

RESUMO: Objetivo: identificar as dificuldades do enfermeiro no gerenciamento da unidade de Pronto-socorro. Método: estudo descritivo, qualitativo, documental. Foi desenvolvido por meio dos portfólios de residentes de enfermagem sobre o trabalho gerencial do enfermeiro entre abril a junho de 2016 na unidade de Pronto-socorro de um hospital de ensino público do interior do Paraná, Brasil. Aos registros dos portfólios, empregou-se Análise de Conteúdo na modalidade temática. Resultados: emergiram três categorias, que se relacionam às dificuldades na dinâmica de funcionamento da unidade, na gestão de pessoas e no gerenciamento de recursos materiais. Conclusão: as dificuldades enfrentadas ratificam a contingência e a complexidade da gerência, algumas vezes superando a governabilidade do enfermeiro. Entretanto, especialmente no manejo de recursos, é necessário que o profissional se utilize mais racionalmente dos meios e instrumentos gerenciais em prol do cuidado qualificado.

Descritores: Pesquisa em administração de enfermagem; Supervisão de enfermagem; Enfermagem em emergência; Gerenciamento de prática profissional.

ABSTRACT: Aim: to identify the difficulties of the nurse in the management of the Emergency Room. Method: descriptive, qualitative and documentary study. It was developed through the portfolios of nursing residents about the management work of nurses from abril to june 2016 in the emergency room of a public university hospital in the interior of Paraná, Brazil. Content Analysis in the thematic mode was used to analyse the records of observations and portfolio. Results: three categories, which are related to the difficulties in emergency room operation dynamics, managing people and managing material resources, emerged. Conclusion: the difficulties experienced ratify the management contingency and complexity, which sometimes surpass the nurses' governance. However, especially in the resources management, it

\footnotetext{
1 Enfermeira. Especialista em Gerenciamento de Enfermagem em Clínica Médica e Cirúrgica, Universidade Estadual do Oeste do Paraná - Unioeste, Cascavel, PR, Brasil. Email: thaisvbugs@yahoo.com.br

2 Enfermeira. Especialista em Gerenciamento de Enfermagem em Clínica Médica e Cirúrgica, Universidade Estadual do Oeste do Paraná - Unioeste, Cascavel, PR, Brasil. Email: denisehoffmannrigo@yahoo.com.br

3 Enfermeira. Especialista em Gerenciamento de Enfermagem em Clínica Médica e Cirúrgica, Universidade Estadual do Oeste do Paraná - Unioeste, Cascavel, PR, Brasil. Email: cristina_bohrer@hotmail.com

${ }^{4}$ Enfermeira. Mestranda em Enfermagem. Universidade Federal do Paraná - UFPR, Curitiba, PR, Brasil. Email: fabieliborges@yahoo.com.br

${ }^{5}$ Enfermeiro. Doutorando em Enfermagem. Universidade Estadual de Maringá. Maringá, PR, Brasil. Email:joaolucascampos@hotmail.com

${ }^{6}$ Enfermeira. Doutora em Enfermagem Psiquiátrica. Docente da Universidade Estadual do Oeste do Paraná.

Cascavel, PR, Brasil. Email: nelsitonini@hotmail.com
} 


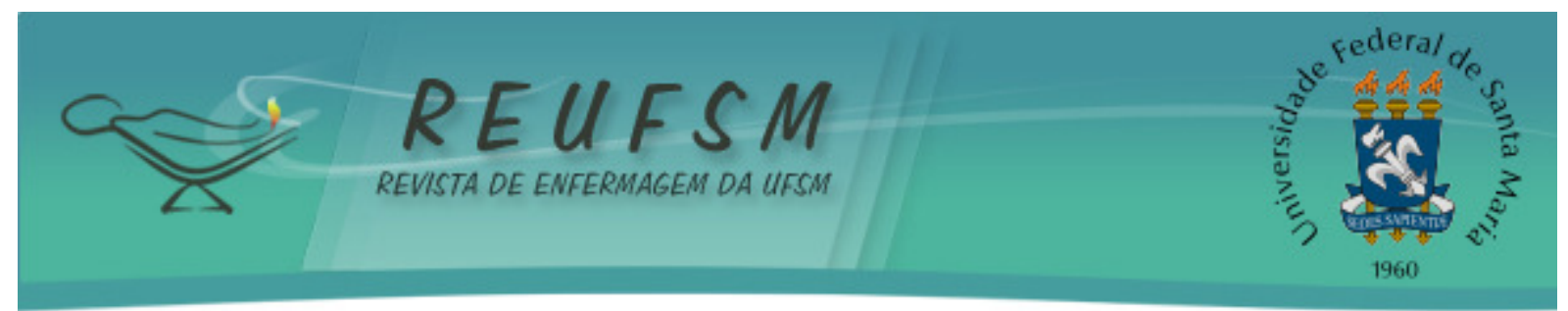

is necessary that the professional uses the management tools more rationally, aiming a qualified care.

Descriptors: Nursing administration research; Nursing, supervisory; Emergency nursing; Practice management.

RESUMEN: Objetivo: identificar los desafíos de los enfermeros en la gerencia de una unidad de urgencias. Método: Estudio descriptivo, cualitativo y documental. Fue desarrollado a partir de los portafolios de residentes de enfermaría sobre el trabajo de dirección del enfermero, entre abril y junio 2016, en un servicio de urgencias de un hospital público de enseñanza en el Estado del Paraná, Brasil. A los registros de las observaciones en diario de campo, se utilizó análisis de contenido en la modalidad temática. Resultados: fueron identificadas tres categorías que refieren las dificultades en la dinámica de funcionamiento de la unidad, de la gestión de personas y de la gestión de recursos materiales Conclusión: las dificultades encontradas confirman la complejidad del trabajo de gestión, a veces, este supera la capacidad de gerencia del enfermero. Sin embargo, especialmente en la gestión de recursos, es necesario que el profesional utilice de forma racional los medios y herramientas de gestión de comunicación en favor de la atención cualificada.

Descriptores: Investigación en administración de enfermería; Supervisión de enfermería; Enfermería de urgencia; Gestión de la práctica professional.

\section{INTRODUÇÃO}

As constantes mudanças nos serviços de saúde, em termos de alocação de recursos e organização de processos de cuidado, impõem modificações no trabalho de enfermagem, o que por consequência alavancam a importância da dimensão gerencial do seu labor. Neste aspecto, o perfil do enfermeiro se torna amplo no que se refere ao desempenho de suas competências, vislumbrando a conciliação entre habilidades, conhecimento e atitudes do agir profissional que se desdobram em ações estratégicas em prol do cuidado. ${ }^{1}$

A atuação do enfermeiro no que tange a dimensão gerencial está relacionada com as atividades de organização do trabalho e de recursos humanos da equipe de enfermagem, com a finalidade de viabilizar as melhores condições de cuidado aos pacientes e o máximo desempenho dos profissionais, coadunando à satisfação e saúde do trabalhador. ${ }^{1-4}$

Dentre as atividades do enfermeiro incorporaram-se habilidades gerenciais complexas que englobam um conjunto de conhecimentos identificados para: tomar decisões coletivas; ${ }^{5}$ liderar o trabalho assistencial; ${ }^{6}$ planejar, prover a gestão de pessoal e interagir sinergicamente com a equipe de saúde. ${ }^{7}$ Além disso, deve-se manter atualizado para movimentar dados e informações do contexto organizacional, para auxiliar na gestão de materiais, físicos, humanos e financeiros ${ }^{3,7}$ Isso se torna um desafio ainda mais evidente no contexto hospitalar público, onde, os processos de trabalho são atribulados e, e em alguns momentos há escassez de insumos materiais ou sub dimensionamento de pessoal.

Ante ao exposto, tem-se que os serviços desempenhados nos prontos-socorros têm caráter de urgência e emergência, não limitando o número de atendimentos e caracterizando-se a entrada mais frequente de pacientes em um hospital. Esses fatores legitimam que o enfermeiro necessita possuir habilidade de planejamento e gerenciamento do serviço, a fim de otimizar a utilização dos recursos disponíveis com máxima eficácia, efetividade e eficiência. ${ }^{8}$

Cabe aludir que as facetas, incluindo as dificuldades, de gerenciamento, são importantes de serem descritas e difundidas, considerando a difusão do conhecimento neste panorama, no qual os processos de tomada de decisão para melhorias no trabalho gerencial poderão ser debruçados com maior assertividade, portanto, estudos nesta área são social e cientificamente relevantes. Ainda, estudos no escopo em pauta, tendem a aumentar o conhecimento gerencial de 


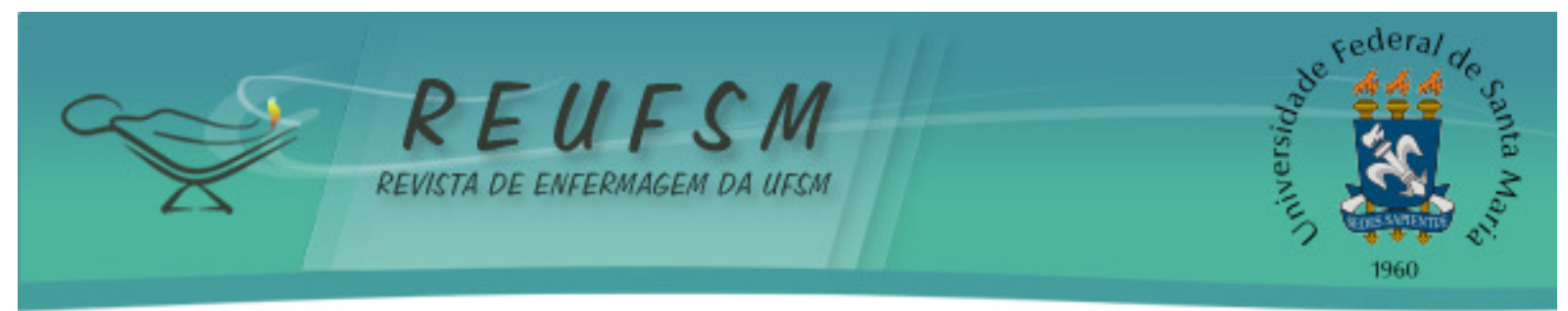

enfermagem em emergência, o que pode favorecer a autonomia do enfermeiro e sua (melhor) definição profissional.

Para tanto, como atribuição legal do enfermeiro exercer o gerenciamento do cuidado seja ele direto ou indireto, ressalta-se a necessidade de visualizar e compreender a dualidade das facilidades e dificuldades em sua jornada laboral e na busca de um trabalho mais construtivo e realizador. ${ }^{9}$

Partindo da premissa de que, mesmo o trabalho gerencial mais habilitado e inovador enfrenta dificuldades devido às contingências próprias da gerência, ${ }^{1,4}$ questiona-se: Como se apresentam as dificuldades do enfermeiro no bojo do seu exercício em uma unidade de Prontosocorro (PS)? Portanto, objetivou- se identificar as dificuldades do enfermeiro no gerenciamento da unidade de Pronto-socorro.

\section{MÉTODO}

Trata-se de um estudo descritivo, de natureza qualitativa, documental, embasado em portfólios referentes a prática em serviço de residentes do Programa de Gerenciamento em Enfermagem em Clínica Médica e Cirúrgica de uma universidade pública do Paraná. A pesquisa deu-se durante o treinamento em serviço (prática) da Residência na Unidade de Pronto-socorro de hospital de ensino público vinculado à universidade.

O hospital dispõe de 210 leitos exclusivos ao Sistema Único de Saúde (SUS), os quais se destinam para atendimento de uma população de aproximadamente dois milhões de habitantes. Ainda, é campo de ensino na graduação e pós-graduação na saúde, que no caso da Residência, dispõe das especialidades nas áreas de enfermagem, medicina, fisioterapia, farmácia e odontologia.

O PS possui seis quartos (um pediátrico, um masculino, um feminino, um misto, um da ortopedia e um quarto de isolamento) com capacidade para aproximadamente 32 pacientes. Há também uma sala de emergência, na qual são atendidos pacientes graves que necessitam de cuidados semicríticos e/ou intensivos, com cinco leitos. Ademais, o PS possui ainda três consultórios (pediatria, ortopedia e clínica médica) e uma sala de procedimentos.

A coleta de dados foi procedida por meio de análise dos portfólios de quatro enfermeiros residentes referentes ao período de abril a junho de 2016. A prática em serviço dos residentes se dá em 48h semanais, período diurno, sendo que cada um permanece por dois meses na unidade, distribuídos entre PS internamento e sala de emergência. Os portfólios eram baseados nas observações diárias, nos quais eram anotadas as vivências (incluindo as dificuldades de gerência) no qual fazia parte da atividade prática como instrumento de ensino-aprendizagem utilizado no Programa de Residência.

Após a leitura dos portfólios foram identificados e selecionados trechos que tivessem como foco a prática gerencial da unidade, além da dinâmica do processo de trabalho e dos instrumentos e/ou meios utilizados para a gerência do serviço, bem como os relatos de dificuldades observados durante a prática.

Os trechos das anotações alusivas dos portfólios foram submetidos à Análise de Conteúdo, na modalidade temática, respeitando-se as etapas de pré-análise; exploração do material e tratamento dos dados. ${ }^{10}$ Fez-se a descrição de unidades temáticas que aglutinassem assuntos ou questões afins, conforme orienta o referencial metodológico adotado. ${ }^{10}$ Por fim, o corpus analisado passou por avaliação individual de dois docentes da área de Gerenciamento em Enfermagem, a fim de verificar pertinência e conformidade dos temas levantados. Nos resultados, os fragmentos dos portfólios foram identificados como "P" e um número arábico que indica aleatoriamente cada enfermeiro residente que o descreveu.

0 presente estudo respeitou integralmente as exigências éticas dispostas na Resolução 466/2012 do Conselho Nacional de Saúde. Ademais, o projeto de pesquisa foi submetido e 


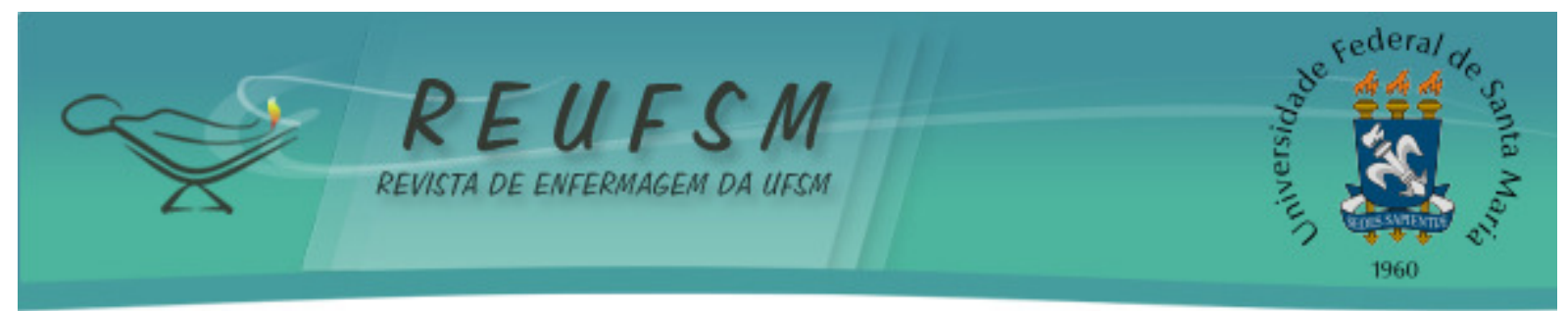

aprovado pelo Comitê de Ética em Pesquisa da Universidade Estadual do Oeste do Paraná, sob protocolo $n^{\circ} 1.450 .491 / 2016$. Os enfermeiros que exerceram preceptoria dos residentes no período da pesquisa assinaram o Termo de Consentimento Livre e Esclarecido.

\section{RESULTADOS E DISCUSSÃO}

Os resultados foram agrupados conforme afinidade dos temas levantados durante a observação e registros dos residentes, os quais foram dispostos em três unidades temáticas que se relacionam às dificuldades do trabalho gerencial do enfermeiro nos seguintes aspectos: Dinâmica de funcionamento da unidade, gestão de pessoas e gerenciamento de recursos materiais.

\section{Dinâmica de funcionamento da unidade: desafio de organização pelo enfermeiro}

O Pronto-socorro é comumente a porta de entrada do hospital, sendo assim, a superlotação é algo rotineiro, ${ }^{8}$ fato também vivenciado e observado na unidade pesquisada:

nessa semana a taxa de ocupação no Pronto-socorro teve sua capacidade máxima, chegando a admitir 60 pacientes. Esse número elevado de pacientes propicia uma assistência inadequada, pois os pacientes não são assistidos de forma integral. (P2)

Estudo realizado no Pronto-socorro de um Hospital filantrópico de Curitiba retrata que o gerenciamento focado nas demandas institucionais gera um fluxo inadequado de atendimento e suscita estagnação dos pacientes internados após serem sanadas as necessidades emergenciais, o que ocorreria por falta de cultura institucional que visa à otimização do serviço de urgência, no que se refere ao gerenciamento de vagas. ${ }^{9}$

O PS campo de estudo tem uma deficiência no fluxo de pacientes, pois não há rotatividade dinamizada, o que se desdobra à descaracterização do setor, uma vez que os pacientes permanecem internados no mesmo, não sendo mais enquadrado como atendimento de emergência. Isso, talvez, possa gerar desmotivação na equipe, pois há acúmulo de trabalho e disfunção do atendimento do Pronto-socorro para o qual é treinado:

hoje o PS estava lotado, a enfermeira estava sozinha, então acabou dando preferência por ficar na sala de emergência com os pacientes críticos e eu [Enfermeira Residente] fiquei no corredor, solicitando sua presença caso precisasse. (P4)

[...] em relação à assistência, esta continuou debilitada em virtude da superlotação de pacientes em ventilação mecânica na Sala de Emergência. (P1)

No contexto do trabalho administrativo analisado, a organização do fluxo do atendimento na unidade é feita por meio de liberação das vagas nas alas, sendo esse um fator dificultador do processo gerencial do enfermeiro, pois o hospital atende média e alta complexidade. Sendo assim, o tempo de internação (média de permanência) dos pacientes é alto, acarretando em um impasse ao encaminhar os usuários alocados no PS para as enfermarias, fato que emergiu como uma barreira gerencial do enfermeiro, que normalmente é encarregado de resolver esta demanda corriqueira.

O fluxo inadequado de pacientes internados já é uma condição em hospitais públicos brasileiros. Uma vez atendidos, os clientes que precisam de internamento tendem a permanecer na unidade de emergência, impossibilitando outros atendimentos. Isso gera uma descaracterização 


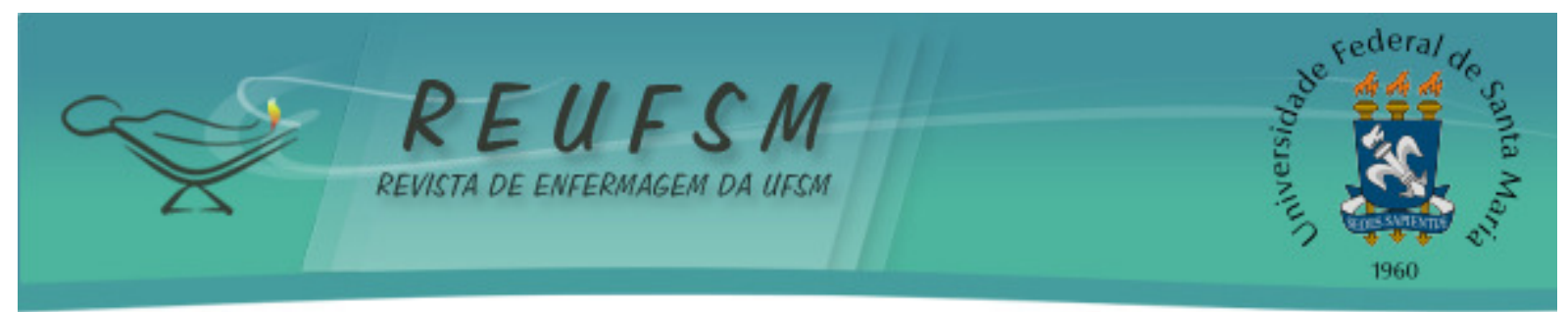

deste serviço e, consequentemente, um desvio das funções emergenciais da equipe de enfermagem, ressaltando que o fluxo de entrada é contínuo e o de saída é lento, ocorrendo uma lotação excessiva, geralmente acima da capacidade do setor. ${ }^{9,11}$

As emergências hospitalares correspondem para grande parte da população a principal alternativa para resolver os problemas de atendimento nos demais níveis de atenção. Esses elementos corroboram para a falta de leitos, a superlotação dos serviços de alta densidade tecnológica, ocasionando inúmeros problemas no atendimento, além de sobrecarga importante ao financiamento do setor saúde. ${ }^{11}$

A unidade de Pronto-socorro é uma das áreas do hospital de grande fluxo, tanto de profissionais quanto de pacientes, além da alta complexidade. Exige assistência integrada, imediata e eficiente, bem como habilidade profissional, conhecimento técnico, e, como já esboçado anteriormente, necessita de franca gestão para articular com os demais setores e agilizar a assistência prestada. ${ }^{12}$

Para garantir uma melhor assistência, a gerência de enfermagem do Pronto-socorro em questão participa ativamente do encaminhamento de exames. Em virtude de ser um hospital escola, alguns atendimentos ocorrem por médicos residentes, sendo assim, procedimentos diagnóstico-terapêuticos de alto custo passam pela Direção Clínica para ser avaliada sua real indicação.

Outro fator a destacar é a articulação com as demais unidades da instituição, visando à otimização das vagas e "giro" de leitos. Neste sentido, alvitra-se que o enfermeiro atuante em Pronto-socorro mobiliza conhecimentos e competências a fim de favorecer a sinergia de seu serviço com outros setores hospitalares, ${ }^{9}$ fato que foi observado, em alguns momentos, durante as atividades vivenciadas na Residência. Contudo, o identificado na unidade de inquérito foi a comunicação falha entre setores hospitalares, o que seria contraproducente atribuir como uma dificuldade gerencial exclusiva do enfermeiro, mas certamente é um problema que merece atenção à sua prática.

[...] uma dificuldade para resolução é a transferência de pacientes do Pronto-socorro para as unidades de internação do hospital, que por vezes se negam em receber pacientes por falta de funcionários disponíveis nos setores. (P1)

O desempenho dos enfermeiros na gerência do cuidado no serviço de emergência está atrelado à busca constante pelo aprimoramento de melhores estratégias que permitam ir além dos desafios impostos por um ambiente de trabalho marcado pela procura constante por atendimento. ${ }^{13}$ Sabendo que o trabalho na saúde é indissociável ao fator humano, tais estratégias comumente estão atreladas às práticas de gestão de pessoas.

\section{Gestão de pessoas: dificuldades percebidas no trabalho do enfermeiro}

O planejamento de um setor de Pronto-socorro é necessário para o funcionamento e organização da unidade. Neste aspecto, à prática laboral, sabe-se que atividades como elaboração de escalas, previsão de férias e cobertura de turnos com déficit de recursos de pessoas fazem parte do cotidiano gerencial do enfermeiro, sendo ferramentas para a busca do cuidado de enfermagem de qualidade em um cenário de adversidades.

Alguns fatores influenciam negativamente o processo gerencial dos recursos de pessoas do PS investigado, entre eles estão, principalmente, o quantitativo de capital humano aparentemente insuficiente em relação à demanda atendida (superlotação); confecção repetida de escalas; o absenteísmo e rotatividade de pessoal; atividades de capacitação em serviço pouco planejadas, 


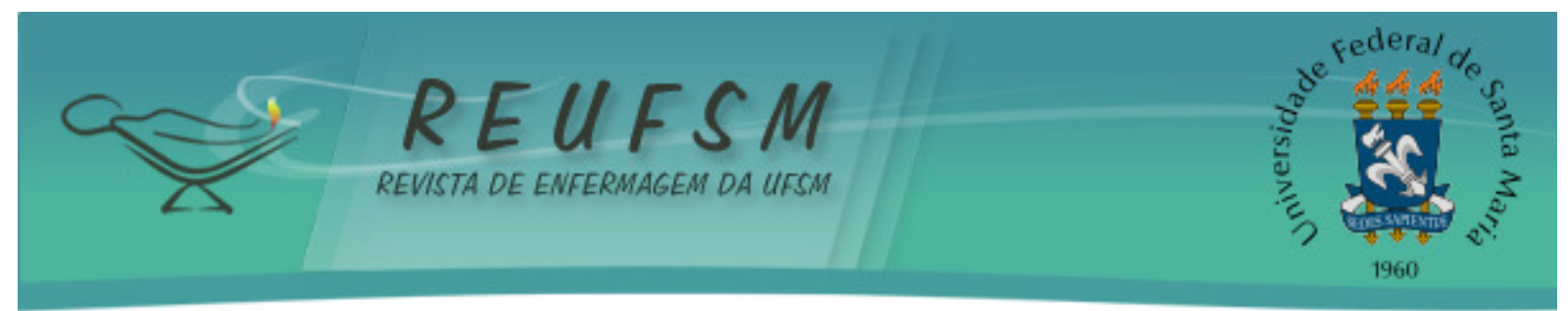

entre outros. Tais dificuldades foram observadas, como atributos a serem manejados pelo coordenador do serviço.

Um fator conflitante foi a ausência do enfermeiro por três dias consecutivos no setor, sendo que o PS ficou sob minha [Enfermeira Residente] responsabilidade. (P2)

[...] percebi que há uma rotatividade elevada de enfermeiros, pois a enfermeira da manhã está de férias. (P4)

Durante o treinamento em serviço pôde-se observar algumas dificuldades (ou deficiências) gerenciais no contexto dos recursos de pessoas, com destaque para o uso acrítico de escala de medida da carga de trabalho da enfermagem. Isso porque, na realidade vivenciada, o grau de complexidade da clientela é usado como mero instrumento burocrático, ou seja, é feito para o cumprimento de rotina, não servindo como variável indispensável ao planejamento e alocação de recursos humanos de enfermagem, como reza a metodologia de dimensionamento de pessoal. ${ }^{2}$

Durante a realização da Nursing Activities Score (NAS) e preenchimento dos dados da unidade nos livros de registro, me questionei sobre sua real importância. Afinal, para qual finalidade estes dados? Uma vez que não há supervisão ou uso dos mesmos. (P1)

[...] a divisão entre pacientes e funcionários não ocorre de forma correta, não é analisado o grau de complexidade de cada paciente, os servidores são divididos por leitos. (P4)

No que se refere ao quantitativo de profissionais, o Pronto-socorro possui 49 funcionários. Apesar de ser um número alto, a taxa de absenteísmo é elevada, pois em alguns turnos o total de funcionários fica reduzido, comprometendo a assistência ao paciente, que normalmente demanda uma carga de trabalho expressiva da equipe de enfermagem. Isso foi observado como uma contingência da gerência do serviço, uma vez que o profissional responsável pelo setor precisa mobilizar recursos humanos de outros setores para atender a clientela normalmente complexa e volumosa, ou, ainda, sobrecarregar mais os funcionários do presente ao labor:

Esse [superlotação de pacientes no corredor do PS] é um problema recorrente que enfrentamos no hospital universitário. Além de ser um problema ao cuidado dos pacientes, é um grande causador de estresse à equipe, que fica sobrecarregada de trabalho e de afazeres ao longo dos turnos. (P3)

$\mathrm{Na}$ gestão de pessoas, o absenteísmo corresponde à ausência dos profissionais de enfermagem no local de trabalho. ${ }^{14}$ No contexto da enfermagem, a carência de funcionários é um importante indicador de qualidade no bojo do manejo de recursos humanos, pois reflete direta ou indiretamente as políticas de valorização do trabalhador e sua satisfação no emprego. ${ }^{15}$

A elaboração da escala de trabalho é um dos quesitos que demandam tempo ao labor gerencial do enfermeiro, em virtude da taxa de absenteísmo alta. Diariamente, é necessário que a escala seja readequada devido ao número de pacientes internados ser incompatível com o número de profissionais presentes, e isso gera conflitos entre os funcionários, pois, esta unidade é gerida como dois setores distintos, porém similares (sala de emergência e PS internamento), sendo acordado em coletividade o rodízio da equipe para exercer as diferentes funções. Isso também foi 


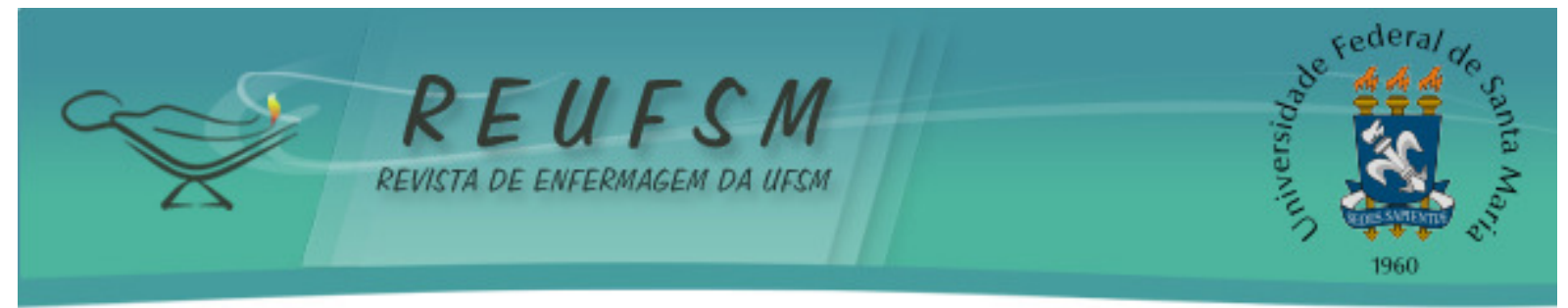

notado como uma dificuldade da ação gerente do enfermeiro, uma vez que os conflitos usualmente eram geridos por imposição.

No âmbito hospitalar, a equipe de enfermagem corresponde ao maior quantitativo organizacional. ${ }^{2}$ Trata-se de profissionais que possuem um ritmo de trabalho acelerado, exaustivo, tenso, com estresse físico e mental, principalmente devido ao contato com o sofrimento e morte, os quais são fatores que contribuem para a ausência/falta de alguns servidores. ${ }^{15-16}$

Atualmente o absenteísmo é um dos grandes indicadores gerenciais, na gestão de pessoas. Ainda, recomenda-se empregar um quantitativo adicional de funcionários para assegurar as ausências, não comprometendo o cuidado prestada aos pacientes, reduzindo, deste modo, os casos de erros relacionados à assistência. ${ }^{17}$

Outro método de favorecer a qualidade da assistência dispensada aos pacientes é por meio da capacitação/atualização dos profissionais envolvidos na prática diária, visando elucidar as dúvidas e os interesses da equipe, aprimorando habilidades e promovendo o conhecimento de novos assuntos, incluindo a gerência do enfermeiro. ${ }^{18}$

As ações de gerência de enfermagem do Pronto-socorro da instituição estudada colaboram para o aprimoramento dos funcionários, autorizando os mesmos a participarem de cursos e especializações, além de ofertar cursos de atualização para equipe, estabelecendo um trabalho de educação continuada no setor. Contudo, por mais que o enfermeiro gerente favoreça o aperfeiçoamento dos profissionais, nem todos os profissionais demonstram interesse em participar das capacitações, fato que sobressaiu-se como outra dificuldade a ser superada no trabalho gerencial do enfermeiro.

Já é de domínio da comunidade científica que o enfermeiro se utilize das ações de capacitação e/ou educação continuada e permanente para a equipe, porque isso, além de se confluir como desenvolvimento de sua competência gerencial, tem potencial para alavancar a qualidade da assistência de enfermagem. Não menos importante, é recomendado que, munido de ampla habilidade gerencial, o enfermeiro planeje, controle e avalie as ações de treinamento ofertadas, para que haja a otimização dos custos necessários para as atividades, bem como o alcance de necessidades reais de aprimoramento da equipe. ${ }^{19}$

\section{Dificuldades relacionadas à gestão de recursos materiais}

Os recursos materiais são essenciais ao funcionamento da instituição hospitalar, estabelecendo infraestrutura indispensável para a prestação do serviço de qualidade. A disponibilidade de equipamentos adequados beneficia a realização das atividades, aumentando a produtividade e minimizando custos; e, dessa maneira, é indispensável o empoderamento do enfermeiro no bojo da gestão de tais suprimentos. ${ }^{20}$

No que se refere a insumos básicos, de apoio à assistência, como seringas, agulhas, instrumental de curativo, o setor não apresenta carência nesse quesito em comparação aos outras unidades de internação, pois como se trata de Pronto-socorro, o material destinado a esse local é dispensado conforme a demanda. Além disso, a unidade possui uma farmácia própria para atender suas necessidades, o que favorece o dinamismo na aquisição dos equipamentos.

Ressalta-se, no entanto, que alguns materiais de suporte à assistência possuem um quantitativo menor, como monitores de parâmetros vitais, ventiladores mecânicos, camas e macas. Essa carência é vivenciada dia-a-dia na sala de emergência da instituição estudada, visto que, a mesma é caracterizada por cinco leitos e se encontra na maioria dos dias além da sua capacidade:

chamou a atenção o fato de ficarmos revezando por algum tempo (uma hora) no "ambu" até encontrar um ventilador disponível por todo o hospital. (P2) 


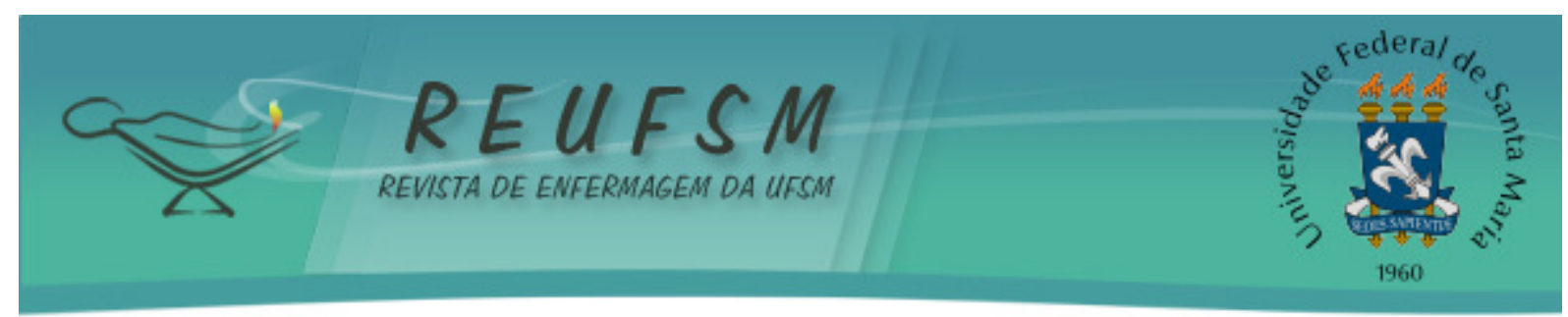

[...] é notória a falta de equipamentos de longa permanência, como: camas, macas, ventilador mecânico, monitor multiparamétrico e bombas de infusão. (P4)

O panorama exposto é evidente em outras instituições do país, visto que os enfermeiros convivem diariamente em condições de conflito, resultando em sofrimento, devido à sobrecarga de trabalho, além da carência de materiais para a assistência dispensada ao usuário, requerendo tomada de decisões que podem resultar em análise ética de conduta. ${ }^{21}$

Compreende-se que a falta desses recursos influencia no método de cuidar, originando desapontamento aos profissionais envolvidos com o atendimento. Porém, mesmo com todos os aspectos desfavoráveis (carência de profissionais, materiais e estrutura física inadequada), a equipe de enfermagem realiza o trabalho da melhor forma possível, porém não garante qualidade no cuidado, devido às dificuldades.

Em relação aos materiais, no sábado teve problemas de falta de estoque, tornando frequente o pedido na farmácia e prejudicando o tempo na assistência. (P1)

No contexto analisado, acredita-se que as dificuldades de gestão de materiais se pautam especialmente no déficit de planejamento do enfermeiro em prol do provimento de estratégias para o cuidado prestado. Neste aspecto, percebeu-se que o profissional não utiliza métodos simples ao exemplo do controle de acervo de materiais, cálculo de consumo médio mensal ou semanal, e provimento de estoque de segurança ${ }^{22}$ que podem ser utilizados com facilidade no seu labor gerencial, mas que por sobrecarga, negligência ou desconhecimento, não são empregados. Apesar disso, cumpre destacar que o suprimento de equipamentos permanentes merece ser revisto pela alta gestão hospitalar, e considera-se que o enfermeiro precisa notificar sempre que necessário a falta destes ao uso assistencial.

\section{CONSIDERAÇÕES FINAIS}

Com este estudo, foi possível se aproximar do conhecimento que permeia as dificuldades de inerência ao trabalho gerencial do enfermeiro em unidade de Pronto-socorro. Os achados ratificaram que tais empecilhos se atrelam à dinâmica de funcionamento da unidade e comunicação entre setores hospitalares; à gestão de pessoas e ao gerenciamento de materiais necessários ao cuidado.

As dificuldades do enfermeiro gestor no Pronto-socorro algumas vezes superam sua governabilidade ou poder de decisão, ao exemplo dos fluxos de atendimento e a comunicação entre unidades externas. Apesar disso, especialmente no contexto da gestão de pessoas e materiais, tais dificuldades talvez possam ser minimizadas com o uso racional de meios e instrumentos disponíveis próprios à gestão, além da mobilização contínua de competências, visando o cuidado qualificado.

Esta pesquisa possui limitações, como, por exemplo, considerar as dificuldades do enfermeiro dissociadas de suas estratégias na gestão da unidade de Pronto-socorro. Por isso, novas pesquisas são necessárias, especialmente àquelas que visem monitorar o impacto da ação gerencial do enfermeiro na qualidade da assistência. Acredita-se, no entanto, que o estudo contribui ao construto do conhecimento da administração em enfermagem, pois descreve algumas dificuldades em coordenar o serviço que podem ser vistas com mais criticidade, além reforçar que o enfermeiro incorpore criticamente os meios, instrumentos e estratégias de coordenador 0 cuidado, a fim de se consolidar como gerente do cuidado. 


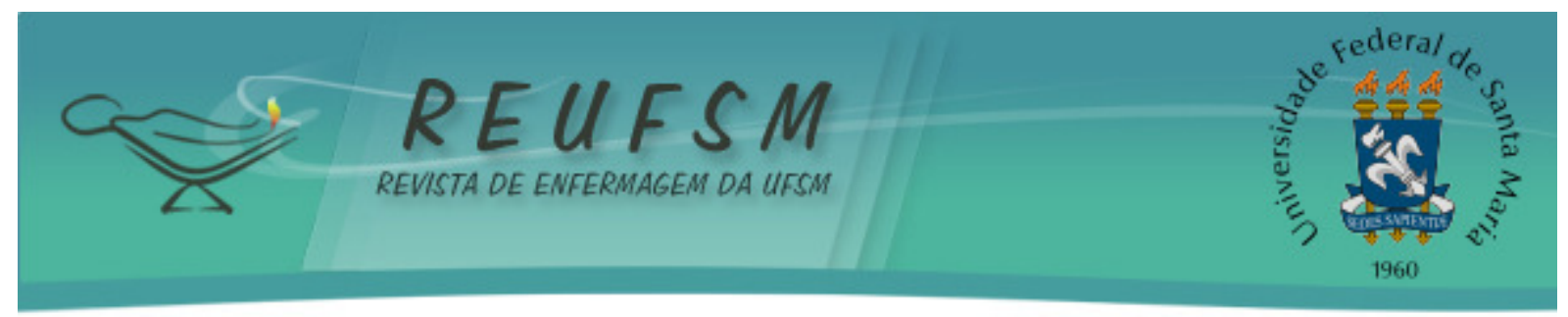

\section{REFERÊNCIAS}

1.Lanzoni GMM, Magalhães ALP, Costa VT, Erdmann AL, Andrade SR, Meirelles BHS. Becoming nursing manager in the nested and complex border of caring and management dimensions. Rev Eletrônica Enferm [Internet]. 2015 [acesso em 2016 ago 18];17(2):322-32. Disponível em: https://www.fen.ufg.br/revista/v17/n2/pdf/v17n2a16-en.pdf.

2. Fugulin FMJ, Rossetti AC, Ricardo CM, Possari JF, Mello MC, Gaidzinski RR. Tempo de assistência de enfermagem em Unidade de Terapia Intensiva: avaliação dos parâmetros propostos pela Resolução COFEN n’293/04. Rev Latinoam Enferm [Internet]. 2012 [acesso em 2016 jun 15];20(2):9 telas. Disponível em: http://www.scielo.br/pdf/rlae/v20n2/pt_15.pdf.

3. Camelo SHH. Competência profissional do enfermeiro para atuar em Unidades de Terapia Intensiva: uma revisão integrativa. Rev Latinoam Enferm [Internet]. 2012 [acesso em 2015 set 10];20(1):192-200. Disponível em: http://www.scielo.br/pdf/rlae/v20n1/pt_25.pdf.

4. Santos JLG, Pestana AL, Guerrero P, Meirelles BSH, Erdmann AL. Práticas de enfermeiros na gerência do cuidado em enfermagem e saúde: revisão integrativa. Rev Bras Enferm [Internet]. 2013 [acesso em 2016 ago 18];66(2):257-63. Disponível em: http://www.scielo.br/pdf/reben/v66n2/16.pdf.

5. Hayashida KY, Bernardes A, Maziero VG, Gabriel CS. Decision-making of the nursing team after the revitalization of a decentralized management model. Texto \& Contexto Enferm [Internet]. 2014 [acesso em 2016 jun 12];23(2):286-93. Disponível em: http://www.scielo.br/pdf/tce/v23n2/0104-0707-tce-23-02-00286.pdf.

6. Amestoy SC, Backes VMS, Trindade LL, Canever BP. Produção científica sobre liderança no contexto da enfermagem. Rev Esc Enferm USP [Internet]. 2012 [acesso em 2016 ago 18];46(1):22733. Disponível em: http://www.revistas.usp.br/reeusp/article/view/40940/44447.

7. Caveião C, Hey AP, Montezeli JH. Administração em enfermagem: um olhar na perspectiva do pensamento complexo. Rev Enferm UFSM [Internet]. 2013 [acesso em 2016 ago 18];3(1):79-85. Disponível em: http://periodicos.ufsm.br/reufsm/article/view/7176/pdf.

8. Galvão J. Gerência de serviço de urgência e emergência: fortalezas e fragilidades. Rev Enferm Integrada [Internet]. 2013 [acesso em 2016 jul 11];6(2):1133-42. Disponível em: http://www.unilestemg.br/enfermagemintegrada/artigo/v6_2/01-gerencia-de-servicos-deurgencia-e-emergencia-fortalezas-e-fragilidades.pdf.

9. Santos JLG, Prochnow AG, Silva DC, Silva MR, Leite JS, Erdmann AL. Prazer e sofrimento no exercício gerencial do enfermeiro no contexto hospitalar. Esc Anna Nery Rev Enferm [Internet]. 2013 [acesso em 2017 maio 27];17(1):97-103. Disponível em: http://www.scielo.br/pdf/ean/v17n1/14.pdf.

10. Bardin, L. Análise de conteúdo. Edições 70: Lisboa; 2011.

11. Montezelli JH, Peres AM, Bernardino E. Demandas institucionais e demandas do cuidado no gerenciamento de enfermeiros em um pronto socorro. Rev Bras Enferm [Internet]. 2011[acesso em 2015 out 23];64(2):348-54. Disponível em: http://www.redalyc.org/pdf/2670/267019461020.pdf.

12. Nugus $P$, Forero R. Understanding interdepartmental and organizational work in the emergency department: an ethnographic approach. Int Emer Nurs [Internet]. 2011 [acesso em 2015 out 16];19(2):69-74. Disponivel

em: https://www.researchgate.net/publication/50988299_Understanding_interdepartmental_and_org anizational_work_in_the_emergency_department_An_ethnographic_approach. 


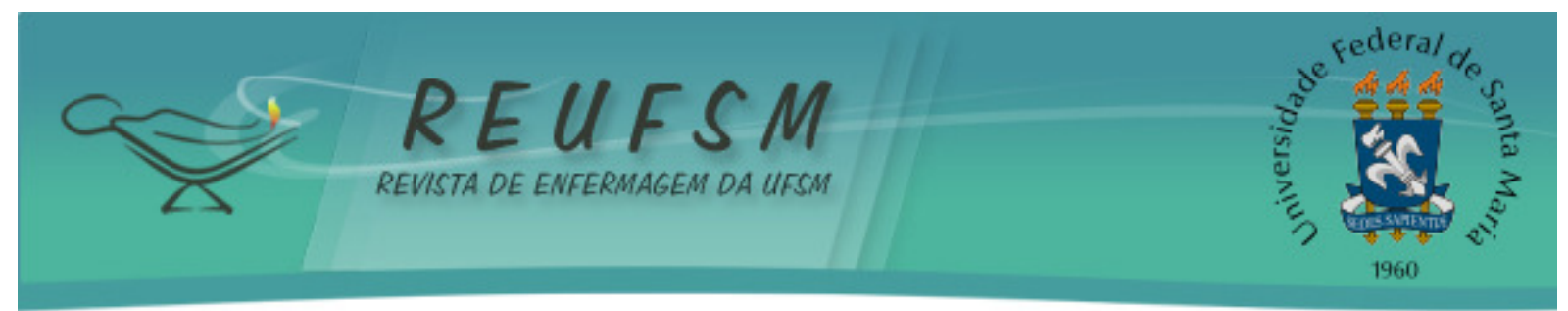

13. Martins JT, Bobroff MCC, Andrade NA, Menezes GDO. Equipe de enfermagem de emergência: riscos ocupacionais e medidas de autoproteção. Rev Enferm UERJ [Internet]. 2014 [acesso em 2016 maio 10];22(3):334-0. Disponível em: http://www.facenf.uerj.br/v22n3/v22n3a07.pdf.

14. Kurcgant P, Passos AR, Oliveira JML, Pereira IM, Costa TF. Absenteísmo do pessoal de enfermagem: decisões e ações de enfermeiros gerentes. Rev Esc Enferm USP [Internet]. 2015 [acesso em 2016 set 05];49:35-41. Disponível em: http://www.scielo.br/pdf/reeusp/v49nspe2/1980-220X-reeusp-49-spe2-0035.pdf.

15. Marques DO, Pereira MS, Souza ACS, Vila VSC, Almeida CCOF, Oliveira EC. O absenteísmodoença da equipe de enfermagem de um hospital universitário. Rev Bras Enferm [Internet]. 2015 [acesso em 2016 jul 15];68(5):594-600. Disponivel em: http://www.scielo.br/pdf/reben/v68n5/0034-7167-reben-68-05-0876.pdf.

16. Magnago TSBS, Lisboa MTL, Griep RH, Kirchhof ALC, Guido LA. Psychosocial aspects of work and musculoskeletal disorders in nursing workers. Rev Latinoam Enferm [Internet]. 2010 [acesso em 2016 maio 23];18(3):429-35. Disponível em: http://www.scielo.br/pdf/rlae/v18n3/19.pdf.

17. Campelo CL, Moura LNB, Silva Junior FJG, Oliveira FDS, Viana LVM, Silva MGP. Absenteísmo na enfermagem: análise do estado da arte. Rev Interd [Internet]. 2016 [acesso em 2017 maio 28];9(1):207-15. Disponível em: http://revistainterdisciplinar.uninovafapi.edu.br/index.php/revinter/article/view/987/pdf_300.

18. Sade PMCS, Peres AM. Desenvolvimento de competências gerenciais do enfermeiro: diretriz para serviços de educação permanente. Rev Esc Enferm USP [Internet]. 2015 [acesso em 2016 set 06];49(6):991-8. Disponível em: http://www.scielo.br/pdf/reeusp/v49n6/pt_0080-6234-reeusp49-06-0991.pdf.

19. Oliveira JLC, Nicola AL, Souza AEBR. Índice de treinamento de enfermagem enquanto indicador de qualidade de gestão de recursos humanos. Rev Enferm UFSM [Internet]. 2014 [acesso em 2016 jun 16];4(1):181-8. Disponível em: http://periodicos.ufsm.br/reufsm/article/view/8772/pdf.

20. Garcia SD, Haddad MCL, Dellaroza MSG, Costa DB, Miranda JM. Gestão de material médicohospitalar e o processo de trabalho em um hospital público. Rev Bras Enferm [Internet]. 2012 [acesso em 2016 ago 18];65(2):339-46. Disponível em: http://www.scielo.br/pdf/reben/v65n2/v65n2a21.pdf.

21. Sakai AM, Rossaneis MA, Haddad MCF, Sardinha DSS. Sentimentos de enfermeiros no acolhimento e na avaliação da classificação de risco em pronto-socorro. Rev Rene [Internet]. 2016 [acesso em 2017 maio 27];mar-abr;17(2):233-41. Disponível em: http://www.periodicos.ufc.br/index.php/rene/article/view/3007/2323.

22. Zuliani LL, Jericó MC, Castro LC, Soler ZASG. Consumo e custo de recursos materiais em unidades pediátricas de terapia intensiva e semi-intensiva. Rev Bras Enferm [Internet]. 2012. [acesso em 2016 ago 18];65(6):969-76. Disponível em: http://www.scielo.br/pdf/reben/v65n6/a13v65n6.pdf.

Data de recebimento: 04/08/2016

Data de aceite: $21 / 06 / 2017$

Autor Correspondente: Thaís Vanessa Bugs

Email: thaisvbugs@yahoo.com.br

Endereço: Rua Sucuri, $n^{\circ}$ 240, Cascavel, Paraná, Brasil

CEP:85805437 